\title{
Oliceridine: A Novel Drug for the Management of Moderate to Severe Acute Pain - A Review of Current Evidence
}

This article was published in the following Dove Press journal: Journal of Pain Research

\author{
Hon Sen Tan' \\ Ashraf S Habib (D) ${ }^{2}$ \\ 'Department of Women's Anesthesia, \\ KK Women's and Children's Hospital, \\ 229899, Singapore; ${ }^{2}$ Department of \\ Anesthesiology, Division of Women's \\ Anesthesia, Duke University Medical \\ Center, Durham, NC, 277I0, USA
}

\begin{abstract}
Optimal pain relief requires a balance between adequate analgesia and risk of adverse effects. Opioids remain the cornerstone for managing moderate to severe pain, but are associated with opioid-induced respiratory depression (OIRD) and gastrointestinal complications. Opioids exert their analgesic effects predominantly via G-protein signaling, however, adverse effects including OIRD are mediated by the $\beta$-arrestin pathway. Oliceridine is the first of a new class of biased opioid agonists that preferentially activate G-protein signaling over $\beta$-arrestin, which would theoretically improve analgesia and reduce the risk of adverse effects. Oliceridine is approved by the Food and Drug Administration (FDA) for the treatment of moderate to severe acute pain. The efficacy of Oliceridine was mainly established in two randomized controlled Phase III clinical trials of patients experiencing moderate to severe pain after bunionectomy (APOLLO-1) and abdominoplasty (APOLLO-2). The results of the APOLLO studies demonstrate that Oliceridine, when administered via patient-controlled analgesia (PCA) demand boluses of $0.35 \mathrm{mg}$ and $0.5 \mathrm{mg}$, provides superior analgesia compared to placebo, and is equianalgesic to PCA morphine $1 \mathrm{mg}$ demand boluses, without significant difference in the incidence of respiratory complications. In a more pragmatic trial of surgical and non-surgical patients, the ATHENA observational cohort study reported rapid onset of analgesia with Oliceridine given with or without multimodal analgesia. However, these studies were designed to evaluate analgesic efficacy, and it is still uncertain if Oliceridine has a better safety profile than conventional opioids. Although several post hoc analyses of pooled data from the APOLLO and ATHENA trials reported that Oliceridine was associated with lower OIRD and gastrointestinal complications compared to morphine, prospective studies are needed to elucidate if biased agonists such as Oliceridine reduce the risk of adverse effects compared to conventional opioids.
\end{abstract}

Keywords: TRV130, biased ligand, opioid agonist, mu-opioid receptor

\section{Introduction}

Opioids remain the cornerstone for analgesic management of moderate to severe acute pain, which affects approximately $75 \%$ of postoperative patients. ${ }^{1}$ Optimal pain relief requires a balance between providing adequate analgesia versus the risk of analgesia-related adverse effects. On one hand, inadequate analgesia has been associated with prolonged hospitalization, impaired recovery, and increased risk of developing chronic pain. ${ }^{2}$ Conversely, excessive opioid use is associated with nausea, vomiting, sedation, constipation, and opioid-induced respiratory depression (OIRD). ${ }^{3-5}$ In particular, OIRD results from a combination of central respiratory
Correspondence: Ashraf S Habib Department of Anesthesiology, Division of Women's Anesthesia, Duke University Medical Center, Box 3094, Durham, NC, 277I0, USA

Tel + I 9196682024

Email ashraf.habib@duke.edu 
depression, sedation, and airway obstruction, potentially leading to hypoxemia, hypercapnia, and cardiorespiratory arrest. $^{6,7}$ The incidence of OIRD ranges from $0.04 \%$ to $41 \%$, depending on the diagnostic criteria, ${ }^{8}$ and places a significant population at risk of morbidity or mortality. ${ }^{9}$ In the last decade, opioid utilization has risen dramatically with concomitant increase in related mortality and adverse effects, which has prompted the search for novel drugs with improved analgesic efficacy and adverse effect profiles.

\section{Clinical Pharmacology}

Conventional opioids such as morphine, oxycodone, and fentanyl exert their analgesic effects by binding to and activating the $\mu$-opioid receptor and its downstream G-protein signaling pathway. ${ }^{10}$ However, the activated $\mu$ opioid receptor can also stimulate an alternative signal transduction pathway mediated by $\beta$-arrestin, which has been implicated in OIRD, gastrointestinal complications, and attenuation of analgesia. ${ }^{11,12}$ The effects of $\beta$-arrestin were demonstrated in $\beta$-arrestin knock-out mice, which exhibited increased analgesia and fewer OIRD and gastrointestinal effects when administered morphine, compared to wild-type mice. ${ }^{13}$ Therefore, preferential activation of the G-protein signaling pathway while minimizing $\beta$ arrestin activity may decrease the risk of opioid-related adverse effects and result in an improved therapeutic window compared to conventional opioids. ${ }^{14}$

Oliceridine (brand name Olinvyk, previously TRV130; Trevena Inc., Pennsylvania, USA) is the first of this new class of opioids, termed biased ligands. Oliceridine is structurally distinct from opiates (eg, morphine) or synthetic derivatives (eg, fentanyl or hydromorphone), and is classified as a biased opioid agonist with exceptional selectivity for the $\mu$-opioid receptor. ${ }^{14}$ Oliceridine has been shown in vitro to induce only $14 \%$ of $\beta$-arrestin signaling activity compared to morphine. ${ }^{14}$

At present, Oliceridine is approved by the Food and Drug Administration (FDA) for intravenous use to treat moderate to severe acute pain. ${ }^{15}$ It is supplied as a colorless, preservative-free solution with each milliliter containing $1 \mathrm{mg}$ of Oliceridine, L-histidine, and mannitol. ${ }^{16}$ An Oliceridine dose of $1 \mathrm{mg}$ is equipotent to $5 \mathrm{mg}$ of intravenous morphine. ${ }^{16}$ After administration, the onset of analgesia occurs rapidly (1 to 2 minutes), peaks at 6 to 12 minutes, and lasts for approximately 1 to 3 hours. ${ }^{15}$ Maintenance of analgesia can be achieved through intermittent boluses or patient-controlled analgesia (PCA). The recommended bolus dose is $1 \mathrm{mg}$ to $2 \mathrm{mg}$ every 1 to 3 hours as needed. ${ }^{15,16}$ For administration via PCA, demand doses of $0.1 \mathrm{mg}$ to $0.35 \mathrm{mg}$ with a 6-minute lockout are recommended. For either bolus or PCA administration, it is recommended that the cumulative daily dose not exceed $27 \mathrm{mg}^{15,16}$

Oliceridine is metabolized by cytochrome $\mathrm{P} 450$ hepatic enzymes, primarily CYP3A4 and CYP2D6 with secondary contributions from CYP2C9 and CYP2C19. The resultant metabolites, M22 and TRV0109662, are inactive, with no appreciable $\mu$-opioid receptor activity found in vitro. ${ }^{16}$ Metabolism may be delayed in individuals classified as poor CYP2D6 metabolizers, who comprise approximately $3 \%$ to $10 \%$ of Caucasians, $2 \%$ to $7 \%$ of African Americans, and $<2 \%$ of Asians in the United States. ${ }^{17}$ Over $70 \%$ of metabolites are eliminated in the urine, with the remainder eliminated in the feces. ${ }^{16}$ Oliceridine has low renal clearance, with $0.97 \%$ to $6.75 \%$ of unchanged drug dose found in the urine, ${ }^{16}$ which is advantageous in patients with significant renal impairment.

\section{Clinical Trials}

\section{Preclinical Studies}

Oliceridine exhibited 3 to 10 times the analgesic potency compared to morphine in mouse and rat analgesic models. ${ }^{14}$ Two studies demonstrate the lack of tolerance with prolonged Oliceridine administration; the first study administered increasing doses of Oliceridine over four days, and reported less tolerance and opioid-induced hyperalgesia compared to morphine in the murine model. ${ }^{18}$ Similar results were obtained from another study involving repeated administration of Oliceridine over three days, which demonstrated prolonged analgesic effects without any significant tolerance during the study period. ${ }^{19}$ Furthermore, Oliceridine induced less allodynia in mice with tibial fractures, compared to morphine which appeared to induce greater nociceptive sensitization. ${ }^{19}$ The analgesic effects of Oliceridine were rapidly and completely reversed by naloxone. ${ }^{14}$

Oliceridine exhibited reduced gastrointestinal adverse effects and respiratory depression in mice, compared to equianalgesic morphine doses. ${ }^{14}$ Continuous infusion of Oliceridine for 28 days in rats and 14 days in monkeys resulted in no unique toxic effects other than those associated with prolonged opioid administration. ${ }^{15}$ In vitro and in vivo genotoxicity assays reported no definitive mutagenicity or clastogenicity. ${ }^{15}$ 


\section{Phase I Studies}

The analgesic efficacy of Oliceridine compared to morphine was evaluated in multiple Phase I studies, including a randomized, double-blind crossover study in 30 healthy volunteers utilizing an experimental model of pain (cold pain test) and ventilatory response to hypercapnia. ${ }^{10}$ The study showed that a single Oliceridine dose of $3 \mathrm{mg}$ or $4.5 \mathrm{mg}$ resulted in improved analgesia with quicker onset, and similar duration of action compared to morphine 10mg. Moreover, Oliceridine had less impact on respiratory drive than morphine, and dose-limiting nausea and vomiting occurred only at supratherapeutic doses of $7 \mathrm{mg} .{ }^{10}$ In another study, a single dose of Oliceridine $3 \mathrm{mg}$ exhibited no clinically significant effect on QT interval, while supratherapeutic doses of $6 \mathrm{mg}$ were associated with transient QT prolongation without significant ventricular arrhythmia. ${ }^{15}$

\section{Phase II Studies}

These initial safety and efficacy results were consistent in two subsequent Phase II randomized-controlled trials of patients undergoing bunionectomy and abdominoplasty, representing surgical models of hard tissue and soft tissue pain, respectively. ${ }^{20,21}$ In the pilot phase of the first study, patients with moderate or severe pain after bunionectomy were randomized to receive intravenous Oliceridine $1 \mathrm{mg}$, $2 \mathrm{mg}, 3 \mathrm{mg}$, or $4 \mathrm{mg} \mathrm{q} 4 \mathrm{~h}$, morphine $4 \mathrm{mg} \mathrm{q} 4 \mathrm{~h}$, or placebo, with the primary endpoint being time-weighted average change in baseline pain scores over 48 hours. ${ }^{20}$ However, the Oliceridine $\mathrm{q} 4 \mathrm{~h}$ regimen was associated with analgesia loss between doses. The study protocol was subsequently altered to compare Oliceridine $0.5 \mathrm{mg}, 1 \mathrm{mg}, 2 \mathrm{mg}$, or $3 \mathrm{mg}$ $\mathrm{q} 3 \mathrm{~h}$ versus morphine $4 \mathrm{mg} \mathrm{q} 4 \mathrm{~h}$ or placebo. Oliceridine $2 \mathrm{mg}$ and $3 \mathrm{mg}$ q $3 \mathrm{~h}$ provided superior analgesia than both placebo and morphine $4 \mathrm{mg} \mathrm{q} 4 \mathrm{~h}$, with similar incidence of adverse effects between all Oliceridine and morphine regimens and no serious adverse events. ${ }^{20}$

The second study was a two-part randomized trial evaluating the efficacy and safety of Oliceridine when administered via PCA in 200 patients experiencing moderate or severe pain after abdominoplasty. ${ }^{21}$ In the first part of the study, patients were randomized to receive two Oliceridine $0.75 \mathrm{mg}$ loading doses 10 minutes apart followed by PCA demand doses of $0.1 \mathrm{mg}$; two morphine $2 \mathrm{mg}$ loading doses 10 minutes apart followed by PCA demand boluses of $1 \mathrm{mg}$, or placebo. After interim analysis, the Oliceridine demand dose was increased to $0.35 \mathrm{mg}$ in the second part of the study. Although there was no significant difference in analgesia provided by the Oliceridine and morphine regimens, the former achieved meaningful pain relief quicker than morphine (Oliceridine $0.35 \mathrm{mg}$ : 0.3 hours; morphine $1 \mathrm{mg}$ : 1.0 hour). Furthermore, Oliceridine was associated with lower incidence of nausea (Oliceridine 0.1mg: 41\%; Oliceridine 0.35mg: 46\%; morphine 1mg: 72\%), vomiting (Oliceridine $0.1 \mathrm{mg}$ : $15 \%$; Oliceridine $0.35 \mathrm{mg}: 15 \%$; morphine $1 \mathrm{mg}: 42 \%$ ), and hypoventilation (Oliceridine 0.1mg: 15\%; Oliceridine 0.35mg: $31 \%$; morphine 1mg: $53 \%$ ) compared to morphine. ${ }^{21}$

\section{Phase III Studies}

The results of two randomized controlled Phase III studies; APOLLO-1 (bunionectomy) and APOLLO-2 (abdominoplasty) supported the findings of the Phase II studies. ${ }^{22,23}$ Both studies enrolled patients experiencing moderate or severe pain after their respective surgeries (defined as numerical rating score (NRS) $\geq 4$ for APOLLO-1, and NRS $\geq 5$ for APOLLO-2) who were randomized to receive PCA demand boluses of placebo, morphine $1 \mathrm{mg}$, or Oliceridine $0.1 \mathrm{mg}, 0.35 \mathrm{mg}$, and $0.5 \mathrm{mg}$. The respective regimens were preceded by a clinician-administered loading dose of Oliceridine $1.5 \mathrm{mg}$, morphine $4 \mathrm{mg}$, or volumematched placebo. Blinded clinicians were permitted to administer $\mathrm{q} 1 \mathrm{~h}$ supplemental doses (Oliceridine $0.75 \mathrm{mg}$ or morphine $2 \mathrm{mg}$ ) as needed one hour after the loading dose, although multimodal analgesia was not allowed. The primary objective of both studies was to compare the analgesic efficacy of Oliceridine to placebo, and secondarily, to compare the efficacy of Oliceridine to morphine. Analgesic efficacy was assessed in both studies using treatment response, defined as patients who did not receive rescue analgesia and who experienced $\geq 30 \%$ improvement in time-weighted sum of NRS difference from baseline to the end of the study (48 hours for APOLLO-1 and 24 hours for APOLLO-2).

The results of APOLLO-1 (summarized in Table 1) reported significantly higher treatment response rates in all Oliceridine regimens and the morphine $1 \mathrm{mg}$ regimen compared to placebo. ${ }^{23}$ Furthermore, a similar proportion of patients in the Oliceridine and morphine groups experienced treatment response over the full study period, and fewer patients needed rescue analgesia or discontinued treatment due to lack of efficacy in the Oliceridine and morphine regimens compared to placebo. Patients experienced "meaningful pain relief" within 12 minutes in all Oliceridine regimens, 
Table I Summary of Results from the APOLLO-I Trial

\begin{tabular}{|c|c|c|c|c|c|}
\hline & \multicolumn{3}{|c|}{ Oliceridine PCA Demand Dose } & \multirow{2}{*}{$\begin{array}{c}\text { Morphine PCA } \\
\text { Img Demand } \\
\text { Dose } \\
\text { N = 79 }\end{array}$} & \multirow{2}{*}{$\begin{array}{c}\text { Placebo } \\
\mathbf{N}=79\end{array}$} \\
\hline & $\begin{array}{c}0.1 \mathrm{mg} \\
N=76\end{array}$ & $\begin{array}{c}0.35 \mathrm{mg} \\
N=79\end{array}$ & $\begin{array}{c}0.5 \mathrm{mg} \\
\mathrm{N}=79\end{array}$ & & \\
\hline Treatment response $(\%)^{\mathrm{a}}$ & 50.0 & 62.0 & 65.8 & 71.1 & 15.2 \\
\hline Any adverse event (\%) & 73.7 & 86.1 & 91.1 & 96.1 & 68.4 \\
\hline Any serious adverse event (\%) & 0 & 0 & 0 & 0 & 0 \\
\hline Mean Respiratory Safety Burden, RSB (minutes) ${ }^{\mathrm{b}}$ & 1 & 9 & 15 & 33 & 1 \\
\hline Respiratory Safety Event (RSE) $(\%)^{c}$ & I & 7 & 11 & 14 & 0 \\
\hline Mean duration of RSE (hours) & 2.88 & 3.21 & 5.72 & 5.96 & 0 \\
\hline Oxygen desaturation <90\% (\%) & 3.9 & 10.1 & 13.9 & 19.7 & 1.3 \\
\hline Respiratory rate <8/min (\%) & 0 & 1.3 & 1.3 & 5.3 & 0 \\
\hline Sedation (\%) ${ }^{d}$ & 18.4 & 20.3 & 16.5 & 19.7 & 2.7 \\
\hline Any gastrointestinal adverse event (\%) & 40.8 & 59.5 & 70.9 & 72.4 & 24.1 \\
\hline Nausea (\%) & 35.5 & 55.7 & 63.3 & 64.5 & 24.1 \\
\hline Vomiting (\%) & 17.1 & 39.2 & 40.5 & 50.0 & 6.3 \\
\hline Constipation (\%) & 10.5 & 11.4 & 13.9 & 17.1 & 11.4 \\
\hline Pruritus (\%) & 2.6 & 16.5 & 6.3 & 31.6 & 7.6 \\
\hline Headache (\%) & 25.0 & 25.3 & 32.9 & 30.3 & 30.4 \\
\hline
\end{tabular}

Notes: ${ }^{a}$ Treatment response was defined as meeting all of the following: (I) $\geq 30 \%$ improvement in time-weighted sum of pain intensity difference from baseline; (2) did not receive rescue analgesia; (3) did not discontinue study medication; and (4) did not reach dosing limits. ${ }^{b}$ Respiratory Safety Burden (RSB) was defined as the number of Respiratory Safety Events (RSE) multiplied by mean cumulative duration of RSE. 'RSEs were defined by clinical observations of worsening respiratory status including changes in respiratory rate, presence of oxygen desaturation, and change in the level of sedation. 'Sedation defined as Moline-Roberts Pharmacologic Sedation Scale $\geq 3$.

versus 30 minutes in the morphine regimen, although this was not statistically significant. Similarly, APOLLO-2 (results summarized in Table 2) reported that all Oliceridine regimens produced significantly higher treatment response rates compared to placebo, and the Oliceridine $0.35 \mathrm{mg}$ and $0.5 \mathrm{mg}$ regimens were non-inferior to morphine $1 \mathrm{mg} .{ }^{22}$

Table 2 Summary of Results from the APOLLO-2 Trial

\begin{tabular}{|c|c|c|c|c|c|}
\hline & \multicolumn{3}{|c|}{ Oliceridine PCA Demand Dose } & \multirow{2}{*}{$\begin{array}{c}\text { Morphine PCA } \\
\text { Img Demand } \\
\text { Dose } \\
\text { N = } 82\end{array}$} & \multirow{2}{*}{$\begin{array}{c}\text { Placebo } \\
\mathbf{N}=83\end{array}$} \\
\hline & $\begin{array}{l}0.1 \mathrm{mg} \\
\mathrm{N}=77\end{array}$ & $\begin{array}{l}0.35 \mathrm{mg} \\
N=79\end{array}$ & $\begin{array}{r}0.5 \mathrm{mg} \\
\mathrm{N}=80\end{array}$ & & \\
\hline Treatment response $(\%)^{\mathrm{a}}$ & 61.0 & 76.3 & 70.0 & 78.3 & 45.7 \\
\hline Any adverse event (\%) & 89.6 & 93.7 & 95.0 & 97.6 & 78.3 \\
\hline Any serious adverse event (\%) & 0 & 1.3 & 3.8 & 1.2 & 0 \\
\hline Mean Respiratory Safety Burden, RSB (minutes) ${ }^{\mathrm{b}}$ & 25.8 & 88.8 & 95.4 & 103.2 & 36.0 \\
\hline Respiratory Safety Event (RSE) (\%) ${ }^{c}$ & 7.8 & 21.5 & 22.5 & 26.8 & 6.0 \\
\hline Mean duration of RSE (hours) & 5.51 & 6.88 & 7.07 & 6.40 & 9.88 \\
\hline Oxygen desaturation $<90 \%$ (\%) & 7.8 & 19.0 & 20.0 & 24.4 & 8.4 \\
\hline Respiratory rate $<8 / \min (\%)$ & 0 & 5.1 & 7.5 & 9.8 & 1.2 \\
\hline Sedation (\%) ${ }^{d}$ & 10.4 & 24.1 & 22.5 & 25.6 & 18.1 \\
\hline Any gastrointestinal adverse event (\%) & 49.4 & 65.8 & 78.8 & 79.3 & 47.0 \\
\hline Nausea (\%) & 44.2 & 62.0 & 75.0 & 74.4 & 45.8 \\
\hline Vomiting (\%) & 23.4 & 21.5 & 42.5 & 53.7 & 13.3 \\
\hline Constipation (\%) & 15.6 & 16.5 & 11.3 & 11.0 & 7.2 \\
\hline Pruritus (\%) & 14.3 & 17.7 & 17.5 & 23.2 & 6.0 \\
\hline Headache (\%) & 15.6 & 29.1 & 26.3 & 29.3 & 28.9 \\
\hline
\end{tabular}

Notes: ${ }^{a}$ Treatment response was defined as meeting all of the following: (I) $\geq 30 \%$ improvement in time-weighted sum of pain intensity difference from baseline; (2) did not receive rescue analgesia; (3) did not discontinue study medication; and (4) did not reach dosing limits. ${ }^{b}$ Respiratory Safety Burden (RSB) was defined as the number of Respiratory Safety Events (RSE) multiplied by mean cumulative duration of RSE. 'RSEs were defined by clinical observations of worsening respiratory status including changes in respiratory rate, presence of oxygen desaturation, and change in the level of sedation. ${ }^{\mathrm{d} S e d a t i o n}$ defined as Moline-Roberts Pharmacologic Sedation Scale $\geq 3$. 
Respiratory safety was assessed using respiratory safety burden (RSB), which is the incidence of respiratory safety events (RSE) multiplied by the cumulative duration of these events. RSEs were determined by clinical observation of respiratory rate, oxygen saturation, or sedation using the Moline-Roberts Pharmacologic Sedation Scale. PCA demand boluses were temporarily ceased during RSEs. APOLLO-1 showed a dose-dependent increase in RSB across all Oliceridine regimens, which were not significantly different from morphine $1 \mathrm{mg} .{ }^{23}$ In APOLLO-2, the Oliceridine regimens were not associated with significantly different RSB than placebo, although RSB for the morphine $1 \mathrm{mg}$ regimen was significantly higher than that of placebo. ${ }^{22}$

Gastrointestinal adverse effects increased in a dosedependent manner across all Oliceridine regimens in APOLLO-1, although the odds of requiring rescue antiemetics were significantly lower with all Oliceridine regimens than morphine. ${ }^{23}$ Similar results were reported in APOLLO-2, with a higher incidence of gastrointestinal complications with increasing Oliceridine dose, although the authors noted that numerically lower proportions of patients receiving Oliceridine received rescue antiemetics (0.1mg: 32.5\%; 0.35mg: 55.0\%; 0.5mg: 61.3\%) compared to morphine $(65.1 \%){ }^{22}$

A third Phase III study, ATHENA, was an open-label observational study evaluating the use of Oliceridine in treating moderate or severe pain in 768 patients, of whom $84 \%$ received multimodal analgesia. ${ }^{24}$ Patients enrolled in ATHENA tended to be older, had higher body mass index (BMI), and all had at least one comorbid condition. ATHENA demonstrated the efficacy of Oliceridine in a pragmatic setting comprised both surgical and nonsurgical patients; rapid onset of potent analgesia occurred within 30 minutes, and less than $5 \%$ of patients discontinued the regimen due to lack of efficacy. However, $64 \%$ of patients experienced minor adverse effects, most of which were nausea $(31 \%)$, constipation $(11 \%)$ and vomiting $(10 \%)$, although there was one case of significant respiratory depression and several incidences of QT prolongation without ventricular arrhythmias. ${ }^{24}$ Of note, unlike the earlier Phase III trials, ATHENA was an observational study and had no restrictions on the use of concomitant medications that could have affected the incidence of adverse effects. Nonetheless, findings from ATHENA suggest that Oliceridine alone, or given in the context of multimodal analgesia, was efficacious and generally well tolerated in a wide range of surgical and non-surgical patients.

\section{Adverse Effect Profile}

Preferential activation of G-protein over $\beta$-arrestin signaling pathways should theoretically improve the therapeutic window of Oliceridine by increasing analgesic efficacy and reducing the risk of opioid-related adverse effects. Although Phase I studies suggested that Oliceridine may be associated with lower risk of respiratory depression and gastrointestinal complications compared to morphine, ${ }^{10}$ the incidence of these adverse effects was not directly investigated in subsequent Phase III clinical trials, which were primarily designed to evaluate the analgesic efficacy of Oliceridine.

The APOLLO trials evaluated the same Oliceridine and morphine regimens, and had similar study design and enrolment criteria. Pooling data from the APOLLO trials, Ayad et al performed a post hoc analysis to further compare the respiratory depressant effects of Oliceridine and morphine. ${ }^{25}$ Outcomes included the incidence of RSE, proportion of patients with dosing interruptions (duration when PCA demand boluses were not permitted due to an ongoing RSE), cumulative duration of all dosing interruptions, incidence of oxygen desaturation $<90 \%$, and discontinuation due to respiratory events. Oliceridine was associated with a dose-dependent increase in RSE incidence $(0.1 \mathrm{mg}$ : $4.6 \%, 0.35 \mathrm{mg}: 15.2 \%$, and $0.5 \mathrm{mg} 18.2 \%$ ), all of which were lower than that of morphine $1 \mathrm{mg}$ $(22.8 \%)$. This represents a relative risk reduction of $33 \%$ for Oliceridine $0.35 \mathrm{mg}$ and $20 \%$ for Oliceridine $0.5 \mathrm{mg}$ compared with morphine $1 \mathrm{mg}$. Furthermore, the proportion of patients with dosage interruptions was higher with morphine $1 \mathrm{mg}(21.5 \%)$ compared to Oliceridine $(0.35 \mathrm{mg}$ : $13.9 \%, 0.5 \mathrm{mg}: 15.1 \%$ ), and the cumulative duration of dosing interruptions and desaturation was significantly lower with Oliceridine. Although the authors concluded that Oliceridine had better respiratory safety than morphine, it should be noted that the diagnosis of RSE was based on clinical assessment and intermittent respiratory and sedation monitoring, which may be limited by clinician subjectivity and the possibility that a proportion of RSEs was undetected by intermittent monitoring.

Another post hoc analysis of data from the APOLLO trials and a preclinical study of 30 healthy volunteers compared Oliceridine with morphine using a utility function, which allowed the authors to integrate the effects of coincident beneficial (analgesic) and adverse (respiratory 
depressant) outcomes into a single variable. ${ }^{26}$ Their results suggest that the use of Oliceridine for treating moderate to severe pain has significantly better utility (probability of producing analgesia rather than respiratory depression) over clinically relevant plasma concentrations than morphine.

Bergese et al performed a retrospective study comparing data from the ATHENA trial against a post hoc derived control cohort treated with morphine at a subset of the ATHENA investigational sites during the same period. $^{27}$ This study included patients who underwent general surgery, colorectal, cardiothoracic, bariatric, or orthopedic surgery, with the primary outcome of OIRD incidence; ATHENA used over 100 MedDRA coded terms including hypoventilation, hypoxia, respiratory depression, and respiratory failure, while OIRD was identified in the control cohort using over 29 ICD-9 and ICD-10 codes, including desaturation, dyspnea, and respiratory insufficiency. The Oliceridine cohort had a greater proportion of elderly patients, American Society of Anesthesiologists (ASA) physical status 3, and cases of colorectal surgery, while the control cohort had greater proportion of patients with prior opioid use, and orthopedic surgery. The use of concurrent opioids was not permitted in the Oliceridine group, but $92 \%$ of the control cohort received concurrent opioids, most commonly hydromorphone. After adjusting for these potential confounding factors, Oliceridine use was associated with an OIRD incidence of $8.0 \%$ compared to the control cohort (30.7\%), representing an odds ratio of 0.14 (95\% CI 0.09 to 0.22 ). Subgroup analysis of patients at high risk of respiratory complications such as chronic obstructive pulmonary disease, renal impairment, sleep apnea, and obesity reported reduced risk of OIRD with Oliceridine (OR $0.14,95 \%$ CI 0.09 to 0.22 ) compared to controls treated with conventional opioids.

Another recent post hoc analysis of data from the ATHENA trial examined the incidence of OIRD in older ( $\geq 65$ years old) and/or obese (body mass index, $\mathrm{BMI} \geq 30 \mathrm{~kg} / \mathrm{m}^{2}$ ) patients within 48 hours of receiving Oliceridine. ${ }^{28}$ In this study OIRD was defined as naloxone use, respiratory rate $<10 \mathrm{bpm}$, or oxygen saturation $<90 \%$. Of 724 patients analyzed, $33 \%$ were $\geq 65$ years old and $46 \%$ were obese. OIRD occurred in $14 \%$ of the cohort, with similar incidence between elderly and younger patients $(10.8 \%$ vs $15.1 \%$, OR $0.9,95 \%$ CI 0.4 to 1.1 , $\mathrm{p}=0.11)$, and obese vs non-obese groups $(14.0 \%$ vs $13.4 \%$, OR $1.1,95 \%$ CI 0.7 to $1.6, p=0.80)$. The incidence of
OIRD in patients who were both elderly and obese was 10.8\%. Multivariable analysis identified baseline pain scores $\geq 6$ (OR 1.9, 95\% CI 1.2 to $3.1, \mathrm{p}=0.005$ ) and concomitant use of benzodiazepines and/or gabapentinoids (OR 1.6, 95\% CI 1.0 to 2.6, $\mathrm{p}=0.045$ ) as factors associated with OIRD. The authors concluded that elderly and obese patients were not at increased risk of OIRD when administered Oliceridine. ${ }^{28}$

There are limited data comparing gastrointestinal adverse effects of Oliceridine with morphine. A post hoc analysis of pooled data from the APOLLO trials was conducted by Beard et al, with the primary outcome being the proportion of "complete responders" defined as the proportion of patients not experiencing vomiting and not requiring rescue antiemetics. ${ }^{29}$ Of note, the majority of patients had Apfel score $\geq 3$, indicating they were at high risk of postoperative nausea and vomiting, and no antiemetic prophylaxis was permitted. The results showed significantly increased proportion of complete responders in the placebo (76.4\%) and Oliceridine $(0.1 \mathrm{mg}$ : $68.0 \%$, 0.35mg: $46.2 \%)$ groups, compared to morphine (30.8\%, $\mathrm{p}<0.005)$. After adjusting for equivalent analgesic effect, the combination of all Oliceridine regimens was associated with OR 3.14 (95\% CI 1.78 to 5.56) of achieving complete response compared to morphine in patients who underwent bunionectomy, and 1.92 (95\% CI 1.09 to 3.36) after abdominoplasty. A summary of studies reporting on Oliceridine pharmacological, analgesic and adverse effects is presented in Table 3.

\section{Cautions \\ Pregnancy}

The use of Oliceridine has not been studied in pregnant women or during lactation, hence data on birth defects, miscarriage, and breast milk transfer are lacking. ${ }^{16}$ Pending such data, the FDA cautions that Oliceridine crosses the placenta and may result in respiratory depression or neonatal withdrawal syndrome with prolonged intrapartum use. ${ }^{16}$ Thus, Oliceridine should be administered in pregnant women only if the benefits outweigh potential risks, and its use is not recommended during labor. ${ }^{15,16}$

\section{Renal Impairment}

A Phase I study investigated the safety of a single Oliceridine $0.5 \mathrm{mg}$ dose in patients with end-stage renal disease versus healthy controls. ${ }^{30}$ Commensurate with the minimal renal clearance of Oliceridine, patients with 
Table 3 Summary of Studies Reporting on Oliceridine Pharmacological, Analgesic and Adverse Effects

\begin{tabular}{|c|c|}
\hline \multicolumn{2}{|l|}{ Pharmacological Effects } \\
\hline Onset time ${ }^{15}$ & I to 2 minutes \\
\hline Time to peak effect ${ }^{15}$ & 6 to 12 minutes \\
\hline Duration of effect ${ }^{15}$ & I to 3 hours \\
\hline Potency compared to morphine ${ }^{16}$ & I: 5 \\
\hline Recommended bolus dose $\mathrm{e}^{15,16}$ & I to $2 \mathrm{mg}$ every I to 3 hours \\
\hline Recommended PCA regimen ${ }^{15,16}$ & $\begin{array}{l}\text { Demand doses of } 0.1 \mathrm{mg} \text { to } 0.35 \mathrm{mg} \text { with } 6-\text { minute lockout } \\
\text { Cumulative daily dose should not exceed } 27 \mathrm{mg}\end{array}$ \\
\hline Metabolism $^{16}$ & Hepatic CYP3A4 and CYP2D6 \\
\hline Metabolites $^{16}$ & No active metabolites \\
\hline Dose adjustment for renal impairment ${ }^{30}$ & Not needed in end-stage renal disease \\
\hline Dose adjustment for hepatic impairment ${ }^{30}$ & $\begin{array}{l}\text { Not needed for mild (Child-Pugh score } 5 \text { to } 6 \text { ) or moderate (Child-Pugh score } 7 \text { to } 9 \text { ) } \\
\text { Reduced dose recommended for severe (Child-Pugh score } 10 \text { to I5) }\end{array}$ \\
\hline Drug interactions ${ }^{15,16}$ & $\begin{array}{l}\text { Caution with CYP3A4 and CYP2D6 inhibitors or inducers } \\
\text { Caution with SSRIs, TCAs, MAO-I, 5-HT3 antagonists, tramadol }\end{array}$ \\
\hline \multicolumn{2}{|l|}{ Analgesic Efficacy } \\
\hline $\begin{array}{l}\text { Phase I, randomized crossover } \\
\text { Healthy volunteers }\end{array}$ & $\begin{array}{l}\text { - Single dose Oliceridine } 3 \mathrm{mg} \text { or } 4.5 \mathrm{mg} \text {; vs morphine } 10 \mathrm{mg} \\
\text { - Oliceridine had improved analgesia, quicker onset, and similar duration of action }\end{array}$ \\
\hline $\begin{array}{l}\text { Phase II, randomized-controlled } \\
\text { Patients undergoing bunionectomy }\end{array}$ & $\begin{array}{l}\text { - Oliceridine } 0.5 \mathrm{mg}, 1 \mathrm{mg}, 2 \mathrm{mg} \text {, or } 3 \mathrm{mg} \mathrm{q} 3 \mathrm{~h} \text {; vs morphine } 4 \mathrm{mg} \mathrm{q} 4 \mathrm{~h} \text {; vs placebo } \\
\text { - Oliceridine } 2 \mathrm{mg} \text { and } 3 \mathrm{mg} \text { q3h provided superior analgesia than both placebo and morphine } 4 \mathrm{mg} \mathrm{q} 4 \mathrm{~h}\end{array}$ \\
\hline $\begin{array}{l}\text { Phase II, randomized-controlled } \\
\text { Patients undergoing abdominoplasty }{ }^{21}\end{array}$ & $\begin{array}{l}\text { - Oliceridine loading dose } 1.5 \mathrm{mg} \text {, PCA demand bolus } 0.1 \mathrm{mg} \text { or } 0.35 \mathrm{mg} \text {; vs morphine loading dose } \\
4 \mathrm{mg}, \text { PCA demand bolus Img; vs placebo } \\
\text { - No significant difference in analgesia between Oliceridine and morphine regimens } \\
\text { - Oliceridine achieved analgesia faster than morphine }\end{array}$ \\
\hline $\begin{array}{l}\text { Phase III, randomized-controlled APOLLO-I } \\
\text { Patients undergoing bunionectomy }{ }^{22}\end{array}$ & $\begin{array}{l}\text { - Oliceridine loading dose } 1.5 \mathrm{mg} \text {, PCA demand bolus } 0.1 \mathrm{mg}, 0.35 \mathrm{mg} \text {, or } 0.5 \mathrm{mg} \text {; vs morphine } \\
\text { loading dose } 4 \mathrm{mg}, \text { PCA demand bolus } 1 \mathrm{mg} \text {; vs placebo } \\
\text { - Oliceridine regimens had higher analgesia treatment response than placebo } \\
\text { - Oliceridine } 0.35 \mathrm{mg} \text { and } 0.5 \mathrm{mg} \text { regimens were non-inferior to morphine } 1 \mathrm{mg} \text { regimen }\end{array}$ \\
\hline $\begin{array}{l}\text { Phase III, randomized-controlled APOLLO-2 } \\
\text { Patients undergoing abdominoplasty }\end{array}$ & $\begin{array}{l}\text { - Oliceridine loading dose } 1.5 \mathrm{mg} \text {, PCA demand bolus } 0.1 \mathrm{mg}, 0.35 \mathrm{mg} \text {, or } 0.5 \mathrm{mg} \text {; vs morphine } \\
\text { loading dose } 4 \mathrm{mg} \text {, PCA demand bolus Img; vs placebo } \\
\text { - Oliceridine and morphine regimens had higher analgesia treatment response than placebo }\end{array}$ \\
\hline $\begin{array}{l}\text { Phase III, observational } \\
\text { ATHENA } \\
\text { Surgical and non-surgical patients }{ }^{24}\end{array}$ & $\begin{array}{l}\text { - Oliceridine alone, or with multimodal analgesia } \\
\text { - Rapid onset of analgesia within } 30 \text { minutes } \\
\text { - Less than } 5 \% \text { discontinued due to lack of analgesic efficacy }\end{array}$ \\
\hline \multicolumn{2}{|l|}{ Adverse Effects } \\
\hline $\begin{array}{l}\text { Phase I, randomized crossover } \\
\text { Healthy volunteers }{ }^{10}\end{array}$ & $\begin{array}{l}\text { - Single dose Oliceridine } 3 \mathrm{mg} \text { or } 4.5 \mathrm{mg} \text {; vs morphine } 10 \mathrm{mg} \\
\text { - Oliceridine had less respiratory depression and gastrointestinal complications than morphine }\end{array}$ \\
\hline $\begin{array}{l}\text { Phase I } \\
\text { Healthy volunteers }{ }^{15}\end{array}$ & $\begin{array}{l}\text { - Single dose Oliceridine } 3 \mathrm{mg} \text { had no significant effect on QT interval } \\
\text { - Single dose Oliceridine } 6 \mathrm{mg} \text { associated with transient QT prolongation, without ventricular } \\
\text { arrhythmia }\end{array}$ \\
\hline
\end{tabular}


Table 3 (Continued).

\begin{tabular}{|c|c|}
\hline $\begin{array}{l}\text { Post-hoc analysis } \\
\text { Pooled data from APOLLO-I and APOLLO- } 2^{25}\end{array}$ & $\begin{array}{l}\text { - Oliceridine regimens had lower incidence of respiratory safety events than morphine regimen } \\
\text { - Oliceridine regimens had less dosage interruptions due to respiratory safety events than } \\
\text { morphine }\end{array}$ \\
\hline $\begin{array}{l}\text { Post-hoc analysis } \\
\text { Pooled data from APOLLO-I and APOLLO-2 } \\
\text { and preclinical study }{ }^{26}\end{array}$ & $\begin{array}{l}\text { - Oliceridine regimens had better utility (probability of producing analgesia rather than respira- } \\
\text { tory depression) than morphine }\end{array}$ \\
\hline $\begin{array}{l}\text { Retrospective study } \\
\text { Data from ATHENA trial compared against } \\
\text { post hoc control cohort }\end{array}$ & $\begin{array}{l}\text { - Oliceridine had lower incidence of opioid-induced respiratory depression ( } 8.0 \%, \text { OR } 0.14,95 \% \\
\mathrm{Cl} 0.09 \text { to } 0.22) \text { than control cohort ( } 30.7 \%) \\
\text { - Subgroup analysis of patients at high risk of respiratory complications: Oliceridine had lower } \\
\text { incidence of opioid-induced respiratory depression (OR } 0.14,95 \% \mathrm{Cl} 0.09 \text { to } 0.22) \text { than control }\end{array}$ \\
\hline $\begin{array}{l}\text { Post-hoc analysis } \\
\text { Data from ATHENA trial }{ }^{28}\end{array}$ & $\begin{array}{l}\text { - Factors associated with Oliceridine-induced respiratory depression: baseline pain scores } \geq 6 \\
\text { (OR I.9, } 95 \% \mathrm{Cl} \text { I.2 to } 3.1 \text { ) and concomitant use of benzodiazepines and/or gabapentinoids (OR } \\
\text { I.6, } 95 \% \mathrm{Cl} \text { I.0 to } 2.6 \text { ) }\end{array}$ \\
\hline $\begin{array}{l}\text { Post-hoc analysis } \\
\text { Pooled data from APOLLO-I and APOLLO- } 2^{29}\end{array}$ & $\begin{array}{l}\text { - Oliceridine regimens achieved higher rate of complete response (no vomiting, no rescue } \\
\text { antiemetics) than morphine (bunionectomy: OR } 3.14,95 \% \mathrm{Cl} \text { I.78 to 5.56; abdominoplasty: } \\
\text { OR } 1.92,95 \% \mathrm{Cl} \text { I.09 to } 3.36 \text { ) }\end{array}$ \\
\hline
\end{tabular}

Abbreviation: PCA, patient-controlled analgesia.

end-stage renal disease were found to have similar pharmacokinetics and drug clearance compared to age- and sex-matched normal individuals, hence no dose adjustment is required in this patient population. ${ }^{30}$

\section{Hepatic Impairment}

Patients with mild (Child-Pugh score 5 to 6) to moderate (Child-Pugh score 7 to 9) hepatic impairment exhibit similar peak concentrations and drug clearance compared to normal individuals, although volume of distribution and half-time are increased. No dose adjustment is recommended in patients with mild or moderate hepatic dysfunction, but reduced initial dose and titration of subsequent doses to clinical endpoints are recommended in patients with severe hepatic impairment (Child-Pugh score 10 to 15$).^{30}$

\section{Misuse and Abuse}

Like other opioids, Oliceridine can be subject to abuse, addiction, and criminal diversion, however, the abuse potential of Oliceridine is estimated to be similar to that of morphine at equianalgesic doses. ${ }^{10,15}$ Utilizing a model of intracranial self-stimulation (ICSS), Altarifi et al demonstrated that repeated administration of Oliceridine resulted in similar effects on ICSS as morphine, suggesting comparable reward-enhancing effects of both drugs. ${ }^{19}$ These results are consistent with a clinical study where the Drug Effects Questionnaire (DEQ) was used to evaluate abuse-related subjective effects following Oliceridine administration in healthy volunteers. ${ }^{10}$ The DEQ assesses subjective opioid effects such as feeling "high", liking the drug effect, and wanting more of the drug. At equianalgesic doses of $3 \mathrm{mg}$, Oliceridine resulted in similar abuserelated subjective effects as morphine $10 \mathrm{mg} .{ }^{10}$ Lastly, Zamarripa et al compared the reinforcing effects of Oliceridine to that of oxycodone. ${ }^{31}$ Reinforcement of drug self-administration is the reference standard test for characterizing a drug's abuse potential. ${ }^{32}$ In this study, the reinforcement effects of Oliceridine and oxycodone were found to be equipotent and equally effective when selfadministered by rats. ${ }^{31}$ Taken together, these results suggest that the abuse potential of Oliceridine is comparable to that of non-biased $\mu$-opioid receptor agonists such as morphine or oxycodone.

\section{Drug Interactions}

There are no clinically significant drug interactions specific to Oliceridine. Like other opioids, care must be taken with concomitant administration of Oliceridine with other central nervous system depressants such as sedatives, alcohol, and hypnotics as this may result in exaggerated respiratory depression and sedation. ${ }^{15,16}$

Inhibition of CYP3A4 and CYP2D6 significantly impairs the metabolism of Oliceridine. Concomitant administration of CYP2D6 inhibitors such as paroxetine, fluoxetine, quinidine, and bupropion may increase or 
prolong opioid effects, similar to poor CYP2D6 metabolisers. ${ }^{16}$ Likewise, concurrent use of CYP3A4 inhibitors such as macrolide antibiotics (eg, erythromycin), triazole antifungals (eg, ketoconazole), and protease inhibitors (eg, ritonavir) may increase or prolong therapeutic and adverse effects. Less frequent dosing may be required in these individuals. Conversely, drugs that induce CYP3A4 like carbamazepine, phenytoin, rifampin, and glucocorticoids may reduce the plasma concentration and therapeutic efficacy of Oliceridine. ${ }^{16}$

Serotonin syndrome may ensue if Oliceridine is used concurrently with selective serotonin reuptake inhibitors (SSRIs), tricyclic antidepressants (TCAs), monoamine oxidase inhibitors (MAO-I), 5-HT3 receptor antagonists, and tramadol. ${ }^{16}$ Like other opioids, Oliceridine may reduce the efficacy of diuretics through the release of antidiuretic hormone, or increase the risk of urinary retention and constipation if used together with anticholinergic drugs. $^{16}$

\section{Avenues for Future Research}

It should be noted that much of the available safety data were obtained from preclinical studies, or clinical studies assessing adverse effects as secondary outcomes, with a paucity of prospective studies evaluating the safety profile of Oliceridine as their primary outcome. Although several post hoc analyses were performed on pooled data from the APOLLO and ATHENA trials, these trials had inherent limitations that may influence the accuracy and generalizability of the pooled findings. For instance, the APOLLO trials had different pain enrolment criteria (APOLLO-1: NRS $\geq 4$ within 9 hours after discontinuation of regional anesthesia; APOLLO-2 NRS $\geq 5$ within 4 hours after surgery), utilized different anesthetic techniques (APOLLO-1: regional anesthesia; APOLLO-2: general anesthesia), had different treatment periods (APOLLO-1: 48 hours; APOLLO-2: 24 hours), and comprised predominantly of females (APOLLO-1: 85\%, APOLLO-2: 99\%) and Caucasians (APOLLO-1: 69\%; APOLLO-2: 64\%). Likewise, the ATHENA trial was an open-label cohort study without a concurrent control group. Post-hoc analyses of these studies are therefore limited by the heterogeneity in study design and the influence of potential confounding factors. Furthermore, antiemetic prophylaxis was withheld or not standardized in those studies, limiting the conclusions that could be derived regarding the occurrence of postoperative nausea and vomiting with Oliceridine compared to other conventional opioids.
Future prospective research should therefore focus on confirming if Oliceridine produces clinically significant improvement in the risk of developing respiratory depression and gastrointestinal complications compared to conventional opioids.

Additionally, the safety and efficacy of Oliceridine should be investigated in obstetric and pediatric populations, as these patients are generally considered to be at increased risk of opioid-related adverse effects. The role of Oliceridine in the context of Enhanced Recovery after Surgery (ERAS) protocols should also be delineated, especially since a key tenant of ERAS is the use of multimodal analgesia to reduce opioid utilization and related adverse effects. However, at present, the use of Oliceridine with multimodal analgesia was evaluated only in the ATHENA trial, and more data are needed to ensure the safety and efficacy of Oliceridine when used in conjunction with other analgesics such as acetaminophen and nonsteroidal anti-inflammatory drugs (NSAIDs).

\section{Conclusions}

Although the analgesic efficacy of Oliceridine was established in several clinical studies, and is approved by the FDA for the treatment of moderate to severe acute pain, further prospective studies are required to compare its adverse effect profile to conventional opioids and assess the cost-effectiveness of its use. Furthermore, the use of Oliceridine in obstetric and pediatric populations, and in the context of ERAS protocols should be delineated.

\section{Funding}

This manuscript was supported solely by departmental funds.

\section{Disclosure}

Dr. Habib has received research support from Pacira Biosciences, Heron Therapeutics, BioQ Pharma, and Avanos Inc. He also served on the Advisory Board for Takeda, Heron Therapeutics and Trevena Inc, and is a consultant for Trevena Inc. The authors report no other conflicts of interest in this work.

\section{References}

1. Gan TJ, Habib AS, Miller TE, White W, Apfelbaum JL. Incidence, patient satisfaction, and perceptions of post-surgical pain: results from a US national survey. Curr Med Res Opin. 2014;30(1):149-160. doi:10.1185/03007995.2013.860019 
2. Gan TJ. Poorly controlled postoperative pain: prevalence, consequences, and prevention. J Pain Res. 2017;10:2287-2298. doi:10. 2147/JPR.S144066

3. Wheeler M, Oderda GM, Ashburn MA, Lipman AG. Adverse events associated with postoperative opioid analgesia: a systematic review. J Pain. 2002;3(3):159-180. doi:10.1054/jpai.2002.123652

4. Jalal H, Buchanich JM, Roberts MS, Balmert LC, Zhang K, Burke DS. Changing dynamics of the drug overdose epidemic in the United States from 1979 through 2016. Science. 2018;361 (6408):eaau1184. doi:10.1126/science.aau1184

5. Bedene A, Lijfering WM, Niesters M, et al. Opioid prescription patterns and risk factors associated with opioid use in the Netherlands. $J$ Pain. 2019;2(8):e1910223. doi:10.1001/jamanetworkopen.2019.10223

6. Cashman JN, Dolin SJ. Respiratory and haemodynamic effects of acute postoperative pain management: evidence from published data. Br J Anaesth. 2004;93(2):212-223. doi:10.1093/bja/aeh180

7. Macintyre PE, Loadsman JA, Scott DA. Opioids, ventilation and acute pain management. Anaesth Intensive Care. 2011;39 (4):545-558. doi:10.1177/0310057X1103900405

8. Gupta K, Nagappa M, Prasad A, et al. Risk factors for opioid-induced respiratory depression in surgical patients: a systematic review and meta-analyses. BMJ Open. 2018;8(12):e024086. doi:10.1136/bmjopen-2018-024086

9. Kessler ER, Shah M, Gruschkus SK, Raju A. Cost and quality implications of opioid-based postsurgical pain control using administrative claims data from a large health system: opioid-related adverse events and their impact on clinical and economic outcomes. Pharmacotherapy. 2013;33(4):383-391. doi:10.1002/phar.1223

10. Soergel DG, Subach RA, Burnham N, et al. Biased agonism of the mu-opioid receptor by TRV130 increases analgesia and reduces on-target adverse effects versus morphine: a randomized, double-blind, placebo-controlled, crossover study in healthy volunteers. Pain. 2014;155 (9):1829-1835. doi:10.1016/j.pain.2014.06.011

11. Violin JD, Lefkowitz RJ. Beta-arrestin-biased ligands at seven-transmembrane receptors. Trends Pharmacol Sci. 2007;28 (8):416-422. doi:10.1016/j.tips.2007.06.006

12. Siuda ER, Carr R 3rd, Rominger DH, Violin JD. Biased mu-opioid receptor ligands: a promising new generation of pain therapeutics. Curr Opin Pharmacol. 2017;32:77-84. doi:10.1016/j.coph.2016.11.007

13. Raehal KM, Walker JK, Bohn LM. Morphine side effects in beta-arrestin 2 knockout mice. J Pharmacol Exp Ther. 2005;314 (3):1195-1201. doi:10.1124/jpet.105.087254

14. DeWire SM, Yamashita DS, Rominger DH, et al. A G protein-biased ligand at the mu-opioid receptor is potently analgesic with reduced gastrointestinal and respiratory dysfunction compared with morphine. J Pharmacol Exp Ther. 2013;344(3):708-717. doi:10.1124/jpet.112. 201616

15. Food and Drug Administration. Oliceridine briefing document: FDA advisory committee meeting. 2018. Available from: https://www.fda. gov/media/121230/download. Accessed March 26, 2021.

16. Trevena. Olinvyk prescribing information. Available from: https:// olinvyk.com. Accessed 2020.

17. Bernard S, Neville KA, Nguyen AT, Flockhart DA. Interethnic differences in genetic polymorphisms of CYP2D6 in the U.S. population: clinical implications. Oncologist. 2006;11(2):126-135. doi:10.1634/ theoncologist.11-2-126

18. Liang DY, Li WW, Nwaneshiudu C, Irvine KA, Clark JD. Pharmacological characters of oliceridine, a mu-opioid receptor G-protein-biased ligand in mice. Anesth Analg. 2019;129 (5):1414-1421. doi:10.1213/ANE.0000000000003662

19. Altarifi AA, David B, Muchhala KH, Blough BE, Akbarali H, Negus SS. Effects of acute and repeated treatment with the biased mu opioid receptor agonist TRV130 (oliceridine) on measures of antinociception, gastrointestinal function, and abuse liability in rodents. $J$ Psychopharmacol. 2017;31(6):730-739. doi:10.1177/0269881116689257
20. Viscusi ER, Webster L, Kuss M, et al. A randomized, Phase 2 study investigating TRV130, a biased ligand of the mu-opioid receptor, for the intravenous treatment of acute pain. Pain. 2016;157(1):264-272. doi:10.1097/j.pain. 0000000000000363

21. Singla N, Minkowitz HS, Soergel DG, et al. A randomized, Phase IIb study investigating oliceridine (TRV130), a novel micro-receptor G-protein pathway selective (mu-GPS) modulator, for the management of moderate to severe acute pain following abdominoplasty. J Pain Res. 2017;10:2413-2424. doi:10.2147/JPR.S137952

22. Singla NK, Skobieranda F, Soergel DG, et al. APOLLO-2: a randomized, placebo and active-controlled Phase III Study Investigating Oliceridine (TRV130), a G protein-biased ligand at the mu-opioid receptor, for management of moderate to severe acute pain following abdominoplasty. Pain Pract. 2019;19(7): 715-731. doi:10.1111/papr.12801

23. Viscusi ER, Skobieranda F, Soergel DG, Cook E, Burt DA, Singla N. APOLLO-1: a randomized placebo and active-controlled phase III study investigating oliceridine (TRV130), a G protein-biased ligand at the micro-opioid receptor, for management of moderate-to-severe acute pain following bunionectomy. J Pain Res. 2019;12:927-943. doi:10.2147/JPR.S171013

24. Bergese SD, Brzezinski M, Hammer GB, et al. ATHENA: a phase 3, open-label study of the safety and effectiveness of oliceridine (TRV130), A G-protein selective agonist at the micro-opioid receptor, in patients with moderate to severe acute pain requiring parenteral opioid therapy. J Pain Res. 2019;12:3113-3126. doi:10.2147/JPR. S217563

25. Ayad S, Demitrack MA, Burt DA, et al. Evaluating the incidence of opioid-induced respiratory depression associated with oliceridine and morphine as measured by the frequency and average cumulative duration of dosing interruption in patients treated for acute postoperative pain. Clin Drug Investig. 2020;40(8):755-764. doi:10. 1007/s40261-020-00936-0

26. Dahan A, van Dam CJ, Niesters M, et al. Benefit and risk evaluation of biased mu-receptor agonist oliceridine versus morphine. Anesthesiology. 2020;133(3):559-568. doi:10.1097/ALN.000000000 0003441

27. Bergese S, Berkowitz R, Rider P, et al. Low incidence of postoperative respiratory depression with oliceridine compared to morphine: a retrospective chart analysis. Pain Res Manag. 2020;2020:7492865. doi: $10.1155 / 2020 / 7492865$

28. Brzezinski M, Hammer GB, Candiotti KA, et al. Low incidence of opioid-induced respiratory depression observed with oliceridine regardless of age or body mass index. Pain Ther. 2021:1-7.

29. Beard TL, Michalsky C, Candiotti KA, et al. Oliceridine is associated with reduced risk of vomiting and need for rescue antiemetics compared to morphine: exploratory analysis from two phase 3 randomized placebo and active controlled trials. Pain Ther. 2020. doi:10.1007/s40122-020-00216-x

30. Nafziger AN, Arscott KA, Cochrane K, Skobieranda F, Burt DA, Fossler MJ. The influence of renal or hepatic impairment on the pharmacokinetics, safety, and tolerability of oliceridine. Clin Pharmacol Drug Dev. 2020;9(5):639-650. doi:10.1002/cpdd.750

31. Austin Zamarripa C, Edwards SR, Qureshi HN, Yi JN, Blough BE, Freeman KB. The G-protein biased mu-opioid agonist, TRV130, produces reinforcing and antinociceptive effects that are comparable to oxycodone in rats. Drug Alcohol Depend. 2018;192:158-162. doi:10.1016/j.drugalcdep.2018.08.002

32. Ator NA, Griffiths RR. Principles of drug abuse liability assessment in laboratory animals. Drug Alcohol Depend. 2003;70(3 Suppl):S55S72. doi:10.1016/S0376-8716(03)00099-1 


\section{Publish your work in this journal}

The Journal of Pain Research is an international, peer reviewed, open access, online journal that welcomes laboratory and clinical findings in the fields of pain research and the prevention and management of pain. Original research, reviews, symposium reports, hypothesis formation and commentaries are all considered for publication. The manuscript management system is completely online and includes a very quick and fair peer-review system, which is all easy to use. Visit http:// www.dovepress.com/testimonials.php to read real quotes from published authors. 